\title{
Informational Hygiene as A Medical and Biological Tool for Health Preservation in The Digital Era
}

\author{
Eduard I Denisov* \\ Department of hygiene, FSBI "Scientific Research Institute of Occupational Medicine, Moscow, Russia \\ *Corresponding author: Eduard I Denisov, Department of hygiene, FSBI "Scientific Research Institute of Occupational Medicine, \\ Moscow, Russia. \\ To Cite This Article: Eduard I Denisov. Informational Hygiene as A Medical and Biological Tool for Health Preservation in The Digital Era. Am \\ J Biomed Sci \& Res. 2019 - 4(2). AJBSR.MS.ID.000765. DOI: 10.34297/AJBSR.2019.04.000765
}

Received: July 10, 2019 | Published: July 18, 2019

\begin{abstract}
Brief overview and essay of the issues of digitalization of economy and society is presented. Some technical trends in developing new devices and medical and biological problems and achievements are discussed. The concept of allostasis as new biological approach and information hygiene as new branch of preventive medicine are briefly considered. The need for risk assessment and risk management thru international ISO/IEC standards as well as need for new sanitary supervision systems with appropriate methods, criteria and norms are suggested.
\end{abstract}

Keywords: Robots; Artificial intelligence; Cyber-physical systems; Informational hygiene; Allostasis; medical contraindications; Risk assessment; Standardization.

\section{Introduction}

The digital revolution poses new challenges for physicians and biologists. From hygienic positions, the essence of digitalization of economy and society, and also ethical problems and legal regulation of robots, systems of artificial intelligence (AI), augmented and virtual reality (AR-VR) - generically called cyber-physical systems (CPS) and often mistakenly called robots - ought to be carefully analyzed. Here are intertwined the problems of philosophy, mathematics, physics and engineering. CPSs are used at work and in everyday life, in industry, medicine, education, culture, etc. This new scientific and technical groundwork is developing rapidly, but it is little studied, it does not have many common concepts, which requires special analysis for hygienic regulation. The purpose of the work is to analyze the essence of digitalization of the economy and society, as well as the legal regulation of robotization in terms of the formation of the paradigm of informational hygiene.

\section{The Aim of the Work}

The analysis of digitalization from the standpoint of information hygiene for hygienic regulation. The number of CPS is rapidly growing in the world. In 2017, robot sales increased by $30 \%$ to 381,335 units. The main drivers of this exceptional growth were the metal industry ( $+55 \%)$ and electrical/electronics industry $(+33 \%)$. After crossing the mark of 2 million units in 2017, the operational stock will reach the level of 3 million units in 2020 and approach
3.8 million units in 2021 [1]. The proportion of the safety segment is estimated at $10-20 \%$ of a total robot installation costs for both products and services [2]. The analysis of such dynamic processes encourages consideration of the ethical-philosophical aspects of the evolution of society, labor and hygienic science for the near future. In the 1990s, information ecology began to form and then informational hygiene as a new section of preventive medicine [3]. Asilomar principles of safe, productive, and moral development of AI systems were adopted [4]. Out of 23 of them the 7 principles are of hygienic significance and can serve as the scientific basis for the hygienic assessment of CPS. The issues of the legal regulation of CPS were widely discussed, e.g. the UNESCO draft and the European Parliament resolution, as well as draft laws of the United Kingdom and the United States, the special groups were organized in Parliaments of many countries, including Russian Federation.

\section{Changing Labor World and Workers' Health}

In the world, the nature of labor is changing; it becomes deserted (robotic), waste-free, etc. The role of the intellectual component of labor is growing, which, with an increase in the flow of information, may be accompanied by an increase in neuro-emotional stress of humans. This confirms the logical chain: new technologies - new risk factors - new diseases of workers - new hygienic tasks. The information loads (IL) were studied as a new hygienically significant 
physical factor; methodical materials and computer programs were created to evaluate both the IL itself and the mental load from it; they are included in the electronic library "Occupational Risk". This creates a basis for research to determine the physical criteria for hygienic assessment of IL - textual, audiovisual, and especially from AR-VR devices [3].

\section{The Concept of Allostasis}

From biological point of view the concept of allostasis as a model of predictive regulation [5] and allostatic load (AL) as an integrated clinical measure of the influence of stress factors is of great importance. The evolution of ideas of homeostasis and allostasis in publications are still discussed [6]. The emergence of a synthesis of work on biomarkers, methods of determining of ALs and their assessment for different groups of workers are important. So were devised the algorithm for the calculation of the AL index and its computer implementation for storing data for the purpose of verification of the concept of allostasis and monitoring the health of workers in occupations with high stress and responsibility.

\section{The AR-VR Devices need to be Studied Carefully}

\begin{tabular}{|c|c|c|}
\hline Table 1: Possible disorders of the human body systems when using AR-VR devices. & Adverse effects & Contraindications \\
\hline The human body system & Strain of vision, fatigue & Meniere's syndrome, ear infections \\
\hline Visual & Dizziness, nausea, dysregulation of posture & Claustrophobia, epilepsy \\
\hline Cochleo-vestibular apparatus & Weakness, nausea, urge to vomit, fear & Arterial hypertension, gastrointestinal diseases \\
\hline $\begin{array}{c}\text { Nervous system and mental sphere } \\
\text { Cardiovascular system, gastrointestinal } \\
\text { tract }\end{array}$ & $\begin{array}{c}\text { Increased pulse rate, increased blood pressure, discom- } \\
\text { fort in stomach }\end{array}$ & \begin{tabular}{c} 
and the stom \\
\hline
\end{tabular}
\end{tabular}

These create new risk factors and symptoms of motion sickness as a form of their manifestation. The basic theory is that of sensory conflict and then activation of the optic-vestibular-spinal system; one talks about the "disease of virtual reality". Possible disorders of the human body functions when using AR-VR devices and medical contraindications, as well as health and safety requirements are systematized in Table 1 [4]. All types of robots and AI systems require hygienic assessment. Special attention should be paid to the AR-VR systems, which create specific health risks, especially for vulnerable groups: children, pregnant and breast-feeding women etc. The bases of information hygiene can serve as a tool to preserve the health of workers and the population in the digital age. The methods and criteria for evaluating CPS on the base of information hygiene and specialized hygiene regulations are urgently needed.

\section{Request from NIOSH on the Priorities of Research of Industrial Robots}

The National Institute of Occupational Safety and Health (NIOSH), which belongs to the Centers for Disease Control and Prevention (CDC), created the Center for the Study of professional Robotics (CORR) and requests information to determine the priority areas of research. These are gaps in knowledge on the safety and health of people working with industrial robotics, with a focus on the field of occupational safety and health, which are unlikely to be conducted by other federal agencies, academia, or the private sector. The request was signed by NIOSH Director John J. Howard, CORR's curator is Hongwei Xiao, Ph.D.; CORR funding is provided for by the NIOSH strategic work plan for 2019-2023 [7].

\section{Some National and International Initiatives}

Besides the directions of CORR comments, the main information hygiene (IG) developments in Russia are published [3]. The role of sanitary inspection is noted, along with standardization and regulation by competent authorities: the WHO/ILO Joint Committee on Occupational Health, ISO, IEC, etc. In Russia was established the Technical Committee of Rosstandart TC-194 "Cyber-Physical
Systems", which began with terminology. The project ISO/IEC NP 23894 Artificial Intelligence -- Risk Management is also initiated. These initiatives reflect two mainstreams: occupational safety and health for CPS. In this area it is advisable to conduct largescale physiological and hygienic studies in order to develop guidelines for hygienic assessment and limiting information loads on workers and the public, similar to Russian hygienic guidelines on principles and methods and criteria of work-place health risk assessment: $\mathrm{R}$ 2.2.1766-03 and $\mathrm{R}$ 2.2.2006-05, resp. that are used under Federal Law of December 28, 2013 N 426-FZ "On the special assessment of working conditions". It would be a new tool for introducing occupational risk assessment into the practice of sanitary surveillance for effective risk management and innovation development.

\section{Conclusion}

Informational hygiene is a new direction in occupational health. In recent years, in a number of countries, there has been a change in the structure of occupational morbidity with the shift of the spectrum of occupational and work-related diseases (WHO term, 1985) from the traditional ones (vibration disease, hearing loss, overstrain of organs and systems etc.) to psychosocial and caused by them somatic disorders. The question of information-related disorders is also raised, especially among adolescent workers, that requires participation in medical examinations along with tradition specialists also medical psychologists, etc. In general, we should agree with the OCAEM declaration on the desirability of combining efforts to preserve and promote health both in the workplace and in the environment.

\section{References}

1. (2019) Executive Summary World Robotics 2018 Industrial Robots. Robot Sales 2017: Impressive growth.

2. Forge S, Blackman C (2010) A Helping Hand for Europe: The Competitive Outlook for the EU Robotics Industry Eds: JRC Scientific and technological reports. EUR p. 114. 
3. Denisov EI Robots (2019) Artificial intelligence, augmented and virtual reality: ethical, legal and hygienic issues. Gigiena i Sanitaria (Hygiene and Sanitation, Russian journal) 98(1): 5-10.

4. (2019) Asilomar principles. Research issues, ethics and values, longerterm issues. Future of life Institute.

5. Sterling P (2011) Allostasis: A model of predictive regulation. Physiology \& Behavior 106(1): 5-15.
6. Denisov EI, Pfaf VF, Stepanian IV, Gorokhova CG (2016) The shift of medical and biological paradigm: from homeostasis to allostasis. Neurocomputers: design, application 2: 16-20.

7. (2018) Occupational Robotics Research Prioritization. Docket Number CDC-2018-0046, NIOSH- 313 93(83): 22264-22266. 